\title{
Value versus Growth: Stochastic Dominance Criteria ${ }^{\Delta}$
}

\author{
Abhay Abhyankar ${ }^{\mathrm{a}}$, Keng-Yu Ho ${ }^{\mathrm{b}}$, and Huainan Zhao ${ }^{\mathrm{c}, ~ *}$ \\ ${ }^{a}$ School of Management and Economics, University of Edinburgh, Edinburgh EH8 9JY, UK \\ ${ }^{b}$ Department of Finance, National Central University, Taoyuan 320, Taiwan \\ ${ }^{c}$ Cass Business School, City University, London, EC1Y 8TZ, UK
}

July 2006

\begin{abstract}
In this paper, we investigate the value versus growth strategies from the perspective of stochastic dominance. Using half century US data on value and growth stocks, we find strong evidence that value stocks stochastically dominate growth stocks in all three-order of stochastic dominance relations over the full sample period as well as during economic boom (good) periods. However, there is no significant stochastic dominance relation between value and growth stocks during recession (bad) periods, which is inconsistent with the risk-based predictions but is better explained by behavioral models.
\end{abstract}

JEL Classification: D81; G11; G30

Keywords: Stochastic Dominance; Value Stocks; Growth Stocks; Value Premium

\footnotetext{
${ }^{\Delta}$ We are grateful to Stephen Donald for generously sharing his software.

${ }^{*}$ Corresponding author: Tel: +44-(0)191-334-5433; Fax: +44-(0)191-334-5240.

Email address: huainan.zhao@durham.ac.uk
} 


\section{Introduction}

Both finance professionals and scholars have long been fascinated by the evidence that value-based investment strategies (i.e., buying stocks that have low prices relative to cash flows, earnings, or book value of equity, etc.) outperform the market. A prominent early example of value strategies is Graham and Dodd (1934). More recently, there has been a considerable debate about risk-based and behavioural explanations of why value stocks earn higher average returns than growth stocks. For instance, Fama and French $(1992,1993)$ argue that value stocks are fundamentally riskier, and the value premium is simply a compensation for bearing extra risk. Others, like DeBondt and Thaler (1985) and Haugen (1994), argue that value premiums arise from mispricing when contrarian investors profit by shorting stocks that naïve investors overreact due to misplaced enthusiasm (i.e., growth stocks) and by buying stocks that are out-of-favour (i.e., value stocks). To date, the central question of whether value stocks are fundamentally riskier than growth stocks is still wide open. In this study we make a first attempt to examine this issue through the lens of stochastic dominance. ${ }^{1}$

\footnotetext{
${ }^{1}$ In financial economics, most standard textbooks (e.g., Huang and Litzenberger, 1988; Ingersoll, 1987) devote considerable space to the concept of stochastic dominance. Surprisingly however we see few empirical applications in recent finance literature. Some exceptions include Porter and Gaumnitz (1972), Porter (1973), Joy and Porter (1974), and Tehrenian (1980) and more recently Post (2003) and Fong, Wong, and Lean (2005) among others. We note that the methodology in Post (2003) focuses on portfolio diversification issues by comparing a given portfolio to a set of assets. In our paper, we only compare two return distributions and therefore do not use the linear programming method in Post (2003). Comparisons of income, wealth and earning distributions using tests for stochastic dominance are however common in empirical economics (e.g., Anderson, 1996; Davidson and Duclos, 2000).
} 
In general, an asset or a portfolio is said to stochastically dominate another if an individual receives greater wealth from it in every ordered state of nature ${ }^{2}$. We study, in this paper, whether the distribution of returns to an investment in a value portfolio stochastically dominates an investment in a growth portfolio at first, second, and third orders using recently developed statistical tests. Since the stochastic dominance test is a model free approach, if value stocks stochastically dominates growth stocks, then the value premium is less likely due to omitted risk factors from models of equilibrium but more likely due to misvaluation of the capital markets. Furthermore, if value stocks are fundamentally riskier, they must underperform growth stocks with some frequency, especially in some 'bad' states of world (Lakonishok, Shleifer, and Vishny, 1994). We therefore test also the stochastic dominance relations between value and growth portfolios under various states (good and bad) of the world.

There are several distinct advantages in using stochastic dominance to evaluate the performance between alternate investment strategies. First, it allows us to compare the entire return distributions of two portfolios instead of just the mean or median portfolio returns as used in most conventional studies. Second, it is free from the ambiguous issue of correctly specifying asset pricing models; we can therefore avoid any misadjustment of risk when measuring the value premium. Third, it makes no assumptions about the return distributions and allows for minimal assumptions about investors' utility functions: specifically, (i) non-satiation in the case of first-order stochastic dominance (FOSD), (ii) risk aversion in the case of second-order stochastic (SOSD), and (iii) positive skewness

\footnotetext{
${ }^{2}$ Copeland, Weston, and Shastri (2005, pp.59).
} 
preference in the case of third-order stochastic dominance (TOSD). Despite obvious advantages, surprisingly the stochastic dominance approach has rarely been applied in traditional empirical studies. ${ }^{3}$

Using a stochastic dominance approach, we find strong evidence that value portfolios stochastically dominate growth portfolios in all three-order of stochastic dominance relations for both the full sample (1951-2003) and the sub-sample (1963-1990) periods regardless of the sorting criteria used in defining value and growth stocks. Our results imply that investors would unambiguously prefer a value to a growth portfolio. During economic booms (good periods), we find slightly weaker evidence that value portfolios stochastically dominate growth portfolios in all three orders. However, we do not find any significant stochastic dominance relation between value and growth portfolios during recessions (bad periods). This result indicates that when times are 'bad' and the marginal utility of wealth is high value stocks do not underperform growth stocks, which contradicts the risk-based predictions (Lakonishok, Shleifer, and Vishny, 1994). Overall, our results imply that the widely documented value premium is not simply due to the artefact of misspecified models of equilibrium and/or test statistics. The value premium may well reflect the missing behavioral components from value investors.

The reminder of the paper is organized as follows. Section 2 briefly reviews related prior research on value versus growth strategies. Section 3 describes the data and methodology

\footnotetext{
${ }^{3}$ A notable recent exception is Fong, Wong, and Lean (2005) who apply this approach in studying momentum strategies.
} 
used in the stochastic dominance tests. Section 4 presents and interprets the results. Section 5 concludes the paper.

\section{Review of Prior Research}

It is well documented in the literature that value stocks or stocks with high ratios of bookto-market (BE/ME), earnings-to-price (E/P), or cash flow-to-price (CF/P) earn higher average returns than growth stocks, i.e., stocks with low corresponding ratios (e.g., Rosenberg, Reid, and Lanstein, 1985; Chan, Hamao, and Lakonishok, 1991; Fama and French, 1992, 1993; Lakonishok, Shleifer, and Vishny, 1994). While early studies rely on US stock market data, growing international evidence also supports the existence of value premium (e.g., Chan, Hamao, and Lakonishok, 1991, 1993; Capaul, Rowley, and Sharpe, 1993; Fama and French, 1998). There is however considerable debate as to the underlying reasons behind the observed value premium. It has, for example, been attributed to survivorship bias (e.g., Kothari, Shanken, and Sloan, 1995), to data snooping biases (e.g., Lo and MacKinlay, 1990), to risk-return trade-off (e.g., Fama and French 1992, 1993), and to investor sentiment (e.g., DeBondt and Thaler, 1985; Lakonishok, Schleifer, and Vishny, 1994), etc.

Fama and French $(1992,1993)$ argue that the higher average returns to value stocks reflect underlying risk factors and the market's pricing of those risk. Behavioral economists are, however, not so convinced about this assertion. Recent theoretical models (e.g., Gomes, Kogan and Zhang, 2003; Kogan, 2004; Zhang, 2005) postulate that differences in cyclical behavior in economic fundamentals should emerge across firms depending on their 
respective value-growth status. From an empirical perspective, Petkova and Zhang (2005) find empirical support for these theoretical models in that the fundamentals of value firms respond negatively and rapidly to negative aggregate shocks while they do so only weakly for growth firms. They thus argue that value stocks are riskier than growth stocks in 'bad' times. However, Lakonishok, Shleifer, and Vishny (1994) argue that if value stocks are fundamentally riskier than growth stocks we should observe that value stocks underperform growth stocks in some states of the world particularly in the 'bad' states where "the marginal utility of wealth is high, making value stocks unattractive to risk-averse investors” (Lakonishok, Shleifer, and Vishny, 1994, pp.1564). They find however the opposite

evidence that value stocks outperform growth stocks in the 'bad' years, (i.e., economic recessions or declining stock markets). In short, Lakonishok, Shleifer, and Vishny (1994) find little support that the higher average returns earned by value stocks is due to fundamental risks. To further investigate this issue, we turn, in this paper, to an alternative method to study the relative performance between value and growth portfolios based on the idea of stochastic dominance.

\section{Data and Methodology}

\subsection{Data}

We use monthly stock return data on equally weighted value and growth portfolios based on three valuation ratios: book-to-market (BE/ME), earnings-to-price (E/P), and cash flow- 
to-price $(\mathrm{CF} / \mathrm{P})$. The data are obtained from Kenneth French's website. ${ }^{4}$ We briefly describe this data set below.

The stock portfolios using BE/ME as a criterion are formed at the end of each June using NYSE breakpoints. The BE used is the book equity for the previous fiscal year end, and the ME used is the price times shares outstanding at the end of previous year. The portfolios include all NYSE, AMEX, and Nasdaq stocks that have the above data, and the sample period is from July 1951 to December 2003. The value portfolios (high BE/ME), used in our tests, contain firms in the top 30\% of BE/ME, and the growth portfolios (low BE/ME) contain firms in the bottom 30\%. The value and growth created by sorting stocks on the basis of earnings-to-price (E/P), and cash flow-to-price (CF/P) are also formed on a similar basis to the $\mathrm{BE} / \mathrm{ME}$ portfolios. The earnings used for the earnings-to-price ratio sorts are the earnings before extraordinary items for the previous fiscal year end. The cash flow in the cash flow-to-price sorts is defined as the total earnings before extraordinary items, plus equity’s share of depreciation and deferred taxes (if available) for the previous fiscal year end. The sample period for both $\mathrm{E} / \mathrm{P}$ and $\mathrm{CF} / \mathrm{P}$ portfolios is also from July 1951 to December 2003. In both cases, i.e., earnings-to-price (E/P) and cash flow-to-price (CF/P), the portfolios include all NYSE, AMEX, and Nasdaq stocks. The value portfolios contain firms in the top $30 \%$ of each ratio, and the growth portfolios contain firms in the bottom $30 \%$.

\footnotetext{
4 We are grateful to Kenneth French for providing this data on his webpage: http://mba.tuck.dartmouth.edu/pages/faculty/ken.french/data_library.html.
} 
Table 1 reports the descriptive statistics of the equally weighed value and growth portfolios. Panel A presents the results for the full sample (1951-2003). We find that value portfolios have larger mean monthly returns (ranging from 0.0165 to 0.0167 ) than growth portfolios do (ranging from 0.0093 to 0.0105 ). In Panel B, we again find that value portfolios have larger mean returns (ranging from 0.0164 to 0.0170) compared to growth portfolio (ranging from 0.0088 to 0.0102 ) for the sub-sample period consistent with Lakonishok, Shleifer, and Vishny (1994). For both panels, the standard deviations of value portfolios are lower than those of growth portfolios. Finally, all the value and growth portfolio returns are positively correlated with their first lagged returns, regardless of sample periods and sorting criteria.

\subsection{Methodology}

We begin with a brief description of stochastic dominance relations as applied in our context and next we describe the statistical tests used in our empirical work. Decisionmaking under uncertainty concerns the choice between random payoffs and is an important topic in economics and finance. The idea of stochastic dominance offers a general decision rule provided the utility functions share certain properties. Specifically, we study whether, given investor preferences like non-satiation, risk aversion, or positive skewness preference, the cumulative distribution function of one random variable (in our case the returns to investing in a value portfolio) dominates that of another (in our case the returns to investing in a growth portfolio). ${ }^{5}$ In other words, we examine whether an investor with specific

\footnotetext{
${ }^{5}$ The stochastic dominance approach allows for a more general framework than one that uses only the mean and the variance as measures of comparative risk, since the mean-variance framework implicitly implies that either the utility function is quadratic or the distribution of payoffs is normal.
} 
preferences prefers a portfolio of value stocks relative to an investment in a growth portfolio.

In testing for stochastic dominance, we compare the cumulative distribution function of the portfolio returns of our two candidate portfolios for each of three orders of stochastic dominance. Specifically, we say that a cumulative distribution function $G$ first-, secondand third-order stochastically dominates a cumulative distribution function $F$ if:

$$
\begin{aligned}
& \mathrm{I}_{1}(z ; G) \leq \mathrm{I}_{1}(z ; F), \\
& \mathrm{I}_{2}(z ; G) \leq \mathrm{I}_{2}(z ; F), \\
& \mathrm{I}_{3}(z ; G) \leq \mathrm{I}_{3}(z ; F),
\end{aligned}
$$

where $z$ is the joint ordered data points of the two samples and where:

$$
\begin{aligned}
& \mathrm{I}_{1}(z ; F)=F(z), \\
& \mathrm{I}_{2}(z ; F)=\int_{0}^{z} F(t) d t=\int_{0}^{z} \mathrm{I}_{1}(t ; F) d t, \\
& \mathrm{I}_{3}(z ; F)=\int_{0}^{z} \int_{0}^{t} F(s) d s d t=\int_{0}^{z} \mathrm{I}_{2}(t ; F) d t .
\end{aligned}
$$

$\mathrm{I}_{1}(z ; G), \mathrm{I}_{2}(z ; G)$, and $\mathrm{I}_{3}(z ; G)$ are analogues of Equations (4), (5), and (6) in the case of the cumulative distribution function $G$.

The economic intuition underlining the above definitions of stochastic dominance is as follows. First-order stochastic dominance, as in Equation (1) above, implies that the cumulative density function $G$ is everywhere to the right of cumulative density function $F$. In other words, investors prefer $G$ to $F$ regardless of their risk preferences as long as their utility function is monotonically increasing, i.e. more wealth is better than less. Under 
second-order stochastic dominance, we see from Equation (2) that the area under $G$ is everywhere smaller than that under $F$. In other words, investors who prefer $G$ to $F$ are required to be risk-averse, i.e. investors with monotonically increasing and concave utility function. Finally, third-order stochastic dominance, defined in Equation (3), corresponds to a preference for skewness. In this case, investors will accept small and almost certain loss in exchange for the remote possibility of huge return. ${ }^{6}$ We note here that while lower order stochastic dominance implies higher order stochastic dominance this does not necessarily imply a converse relation.

Barrett and Donald (2003) have recently proposed statistical tests for detecting stochastic dominance. These tests compare the two candidate cumulative distribution functions at all points in the sample and are based on the Kolmogorov-Smirnov (K-S) test commonly used in the statistics literature to compare sample distributions. ${ }^{7}$ The null hypothesis, in these tests, is that cumulative distribution function $G$ stochastically dominates cumulative distribution function $F$ for the $j$ th order (this hypothesis also includes the case where the two distributions are equal everywhere) while the alternative is that stochastic dominance fails at some points. These hypotheses can be more compactly written as:

$$
H_{0}: \mathrm{I}_{j}(z ; G) \leq \mathrm{I}_{j}(z ; F) \text { for all } z \text {, }
$$

\footnotetext{
${ }^{6}$ For example, people who buy lottery tickets or housing insurance exhibit skewness preference. Several authors have proposed asset pricing models that account for skewness preferences. See for example Harvey and Siddique (2000) for reference.

${ }^{7}$ Anderson (1996) and Davidson and Duclos (2000) compare the distribution functions only at a fixed number of arbitrarily chosen points. In general, comparisons using only a small number of arbitrarily chosen points will have low power if there is a violation of the inequality in the null hypothesis on some subinterval lying between the evaluation points used in the test.
} 


$$
H_{1}: \mathrm{I}_{j}(z ; G)>\mathrm{I}_{j}(z ; F) \text { for some } z \text {. }
$$

The Barrett and Donald (2003) test statistic is:

$$
\hat{S}_{j}=\sqrt{\frac{N \times M}{N+M}} \sup _{z}\left(\mathrm{I}_{j}\left(z ; \hat{G}_{M}\right)-\mathrm{I}_{j}\left(z ; \hat{F}_{N}\right)\right),
$$

where the operator $\mathrm{I}_{j}$ are given by:

$$
\begin{aligned}
& \mathrm{I}_{j}\left(z ; \hat{F}_{N}\right)=\frac{1}{N} \sum_{i=1}^{N} \mathrm{I}_{j}\left(z ; 1_{X_{i}}\right)=\frac{1}{N} \sum_{i=1}^{N} \frac{1}{(j-1) !} 1\left(X_{i} \leq z\right)\left(z-X_{i}\right)^{j-1}, \\
& \mathrm{I}_{j}\left(z ; \hat{G}_{M}\right)=\frac{1}{M} \sum_{i=1}^{M} \mathrm{I}_{j}\left(z ; 1_{Y_{i}}\right)=\frac{1}{M} \sum_{i=1}^{M} \frac{1}{(j-1) !} 1\left(Y_{i} \leq z\right)\left(z-Y_{i}\right)^{j-1} .
\end{aligned}
$$

The test statistics for stochastic dominance beyond the first-order (e.g. second- and thirdorder stochastic dominance) do not have closed-form limiting distributions. As a result, pvalues need to be obtained by simulation (e.g., McFadden, 1989). Barrett and Donald (2003) propose two methods to obtain five simulated p-values, by simulation and by bootstrap. We provide the details of the two methods in Appendix A.

We report the results of the statistical tests of stochastic dominance based on the following two-step procedure. First, we test whether the value portfolio stochastically dominates the corresponding growth portfolio. Second, we report the test results for the converse hypothesis, i.e., whether the growth portfolio stochastically dominates the value portfolio. Our statistical test results can be interpreted as follows. If we fail to reject in the first step that value stochastically dominates growth portfolio but reject instead in the second step that growth stochastically dominates value portfolio, we conclude that the value portfolio 
stochastically dominates the growth portfolio. ${ }^{8}$ However, if we reject or fail to reject the null in both steps of the test, we conclude that there is no stochastic dominance relation between the two portfolios.

\section{Empirical Results}

We now turn to the results of our statistical tests for stochastic dominance relations between value and growth portfolios. We follow Fama and French (1992) and Lakonishok, Shleifer, and Vishny (1994, LSV hereafter) and report only results based on equal-weighted portfolios. ${ }^{9}$ We present, in the following tables, the first-, second- and third-order stochastic dominance relations between value and growth portfolios formed on the basis of book-tomarket (BE/ME), earnings-to-price (E/P), and cash flow-to-price $(\mathrm{CF} / \mathrm{P})$ ratios.

\subsection{Results for the Full Sample (1951-2003) and LSV Sample (1963-1990) Periods}

We first report results for the entire sample periods without accounting for different (good or bad) states of world. In addition to the full sample (1951-2003), we also test separately the LSV sample (1963-1990) as a robustness check. Table 2 presents the test results for the full sample. It clearly shows that value portfolios stochastically dominate growth portfolios in all the first-, second- and third-order regardless of the sorting criteria (i.e., BE/ME, E/P,

\footnotetext{
${ }^{8}$ Alternately, if we fail to reject in the second step that the growth stochastically dominates the value portfolio but can reject in the first step that the value stochastically dominates the growth portfolio, we conclude that there is a stochastic dominance relation of growth over the value portfolio.

${ }^{9}$ We also calculate the results using value-weighted scheme. They are however qualitatively similar to the equally weighted cases. For brevity, we report only the equally weighted results. The value-weighted results are available upon request.
} 
and $\mathrm{CF} / \mathrm{P}$ ) used in defining value and growth stocks. More specifically, in all cases we fail to reject the null that value portfolios stochastically dominate growth portfolios but reject strongly (at $1 \%$ significance level) the null that growth portfolios stochastically dominant value portfolios. These results provide strong evidence that value stocks dominate growth stocks over the full sample periods.

Table 3 reports the subperiod test results for the LSV sample (1963-1990). We again find strong evidence that value portfolios stochastically dominate growth portfolios in all three orders, since we fail to reject the null that value portfolios stochastically dominate growth portfolios but reject (at 5\% significance level) the alternative that growth portfolios stochastically dominate value portfolios. Though the significance level for the subperiod is a bit lower than that for the full sample period (5\% compared to $1 \%$ significance level), still the results show a strong dominance relation of value over growth strategies. Overall, Tables 2 and 3 demonstrate investors' strong preference of adopting a value strategy that is buying value stocks and sell growth stocks over the entire sample period.

A few points may be noted from the results after accounting for investor preferences. First, results of the first-order stochastic dominance indicate that investors who prefer more to less would have preferred value to growth stocks. Second, the second-order stochastic dominance results imply that risk-averse investors would have favoured value to growth stocks. Third, investors who have positive skewness preference would also have chosen to buy value and sell growth stocks as indicated by the third-order stochastic dominance relations. 
In sum, our test results for the full sample (1951-2003) and LSV sample (1963-1990) periods show clear evidence of the existence of significant value premium. These results cast serious doubt on the risk-based arguments that the value premium is due simply to omitted risk factors in existing asset pricing models. Next, we look at the question one step further by examining the value versus growth strategies under different (good and bad) states of world.

\subsection{Results under Different States of World}

The risk-based explanation of the value premium suggests that value stocks are fundamentally riskier than growth stocks. If this is true, value stocks must underperform growth stocks with some frequency, especially in some 'bad' states of world. We therefore, in this section, test for the stochastic dominance relations between value and growth portfolios under various states (good and bad) of the world. We use the National Bureau of Economic Research (NBER) business cycle reference dates to determine the periods of boom and recession. ${ }^{10}$

\footnotetext{
${ }^{10}$ For the full sample period (1951-2003), there are ten boom periods (1951/07-1953/07, 1954/06-1957/08, 1958/05-1960/04, 1961/03-1969/12, 1970/12-1973/11, 1975/04-1980/01, 1980/08-1981/07, 1982/12-1990/07, 1991/04-2001/03, 2001/12-2003/12) and nine recession periods (1953/08-1954/05, 1957/09-1958/04, 1960/05-1961/02, 1970/01-1970/11, 1973/12-1975/03, 1980/02-1980/07, 1981/08-1982/11, 1990/08-1991/03, 2001/04-2001/11) based on NBER business cycle reference dates. For LSV sample period (1963-1990), there are five boom periods (1963/04-1969/12, 1970/12-1973/11, 1975/04-1980/01, 1980/08-1981/07, 1982/121990/04) and four recession periods (1970/01-1970/11, 1973/12-1975/03, 1980/02-1980/07, 1981/081982/11).
} 


\subsubsection{Results for the Boom (Good) Periods}

We note, before going into the details, that the stochastic dominance relations between value and growth portfolios in the boom periods (Tables 4 and 5) are slightly weaker than that of the corresponding full sample (1951-2003) and the LSV sample (1963-1990) periods reported earlier (Tables 2 and 3). As we observe that most of the stochastic dominance relations (irrespective of their orders) reported in Table 2 and 3 are statistically significant at $1 \%$ or $5 \%$ significance levels, our test results for the boom periods, especially for the LSV sample boom periods (Table 5), are however only significant at the $5 \%$ or $10 \%$ significance level. The boom period results are nonetheless consistent with most theoretical interpretations and empirical findings in that risk/return dispersions between stocks are lower in good times (Zhang, 2005). It is thus not difficult to understand why investors (regardless of the orders of stochastic dominance) exhibit only a weak preference between value and growth stocks in the 'good' states of world.

Table 4 reports the stochastic dominance test results for the boom periods of the full sample (1951-2003). It shows that all value portfolios stochastically dominant growth portfolios with at least 5\% significance level under all three orders of stochastic dominance relations regardless the sorting criteria used in defining value or growth stocks. Table 5 presents the test results for the LSV sample (1963-1990) boom periods and mirrors the findings reported in Table 4. Though the stochastic dominance relations are a bit weaker comparing to Table 3, all three-order relations are nonetheless significant at $10 \%$ significance level. Our results show that value portfolios still dominate growth portfolios when the time is 'good' and investors' marginal utility of wealth is low. It demonstrates that in economic boom periods value stocks are more preferable than growth stocks regardless of investors' preferences, 
that is, non-satiation for the first-order, risk averse for the second-order, or favoring positive-skewed returns for the third-order.

\subsubsection{Results for the Recession (Bad) Periods}

Tests for the recession periods lie in the center of the ongoing debate between risk- and behavioral-based models. LSV argue that if value stocks are indeed riskier than growth stocks, we should observe that value stocks underperform growth stocks in the 'bad' states of the world where the marginal utility of wealth is high and therefore making value stocks unattractive to risk-averse investors. In their tests, LSV find opposite evidence, i.e., value stocks outperform growth stocks in the 'bad' states of world and thus question the riskedbased models in resolving the value premium puzzle. Given the advantages of stochastic dominance approach, we set out to reexamine this issue by studying the stochastic dominance relations between value and growth portfolios during the 'bad' states of world.

Tables 6 and 7 report the stochastic dominance test results under the 'bad' states of world for both the full and LSV sample periods. We find there are no significant stochastic dominance relations between value portfolios and growth portfolios under all three orders for the recession periods. More specifically, in all cases we fail to reject both the null that value portfolios stochastically dominate growth portfolios and the alternative that growth portfolios stochastically dominate value portfolios. Therefore, no stochastic dominance relations have been identified between value and growth portfolios in the 'bad' periods.

In order to conduct a robustness check for above results, we also examine the stochastic dominance relations during the 'bad' states of world defined by the real GDP growth rate. 
In line with LSV, we use quarterly GDP growth data and classify the data (1951-2003) into four states of the world. Two of the states are the worst 10 quarters with the lowest GDP growth and the best 10 quarters with the highest GDP growth. The rest of the data are evenly classifies into the 95 next worst and the 95 next best quarters. For the worst quarters of GDP growth, we again find no significant stochastic dominance relations between value and growth portfolios for all three orders of stochastic dominance tests. ${ }^{11}$

Our evidence together for the 'bad' periods fail to support the risk-based expectation that value stocks are less preferred to growth stocks in 'bad' states of world since no significant stochastic dominance relations between value and growth portfolios have been found under two independent tests with different definition of the 'bad' states of world. Therefore the risk-based explanations to the value premium puzzle are questionable.

\section{Conclusions}

In this paper, we study the value versus growth strategies under the perspective of stochastic dominance. Specifically, we test for stochastic dominance relations between return distributions of investments in value versus growth portfolios. A distinct advantage of this approach is that it does not require the use of any specific asset pricing model to correct for risk and it makes minimal assumptions about the return distributions and/or investor risk preferences. Furthermore, it compares the entire return distributions of portfolios rather than only the mean or median returns as normally used.

\footnotetext{
${ }^{11}$ For space purpose, we do not report the GDP test results here. However, the results are available upon request.
} 
Using half century US data on value and growth stocks, we find strong evidence that value stocks stochastically dominate growth stocks in all three-order of stochastic dominance relations over both the full sample period (1951-2003) and the subsample period (19631990). The same results also hold true for the tests of economic boom (good) periods. However, we do not find any significant stochastic dominance relations between value and growth stocks in recession (bad) periods which is inconsistent with the risk-based predictions that value stocks underperform growth stocks when the time is 'bad' and the marginal utility of wealth is high. Overall, our results indicate that the widely documented value premium is not due simply to the artefact of misspecified models of equilibrium and/or test statistics. The behavioral-based explanation to the value premium is more closely supported by the data. 


\section{Appendix A}

Based on Barrett and Donald (2003), there are two test statistics using simulation method. The first test statistic using simulation (KS1) to obtain the exact p-values is:

$$
\bar{S}_{j}^{F}=\sup _{z}\left(\mathrm{I}_{j}\left(z ; \mathrm{B}^{*} \circ \hat{F}_{N}\right)\right),
$$

where $\mathrm{B}^{*} \circ \hat{F}_{N}$ is an independent Brownian Bridge process. By denoting $\left\{U_{i}\right\}_{i=1}^{N}$ as sequence of i.i.d. standard normal random variables that are independent of the samples, we can then give the process $\mathrm{B}^{*} \circ \hat{F}_{N}$, evaluated at each value of $z$, as $\mathrm{B}^{*}\left(z ; \hat{F}_{N}\right)=\frac{1}{\sqrt{N}} \sum_{i=1}^{N}\left(1\left(X_{i} \leq z\right)-\hat{F}_{N}(z)\right) U_{i}$.

The second test statistic using simulation (KS2) is:

$$
\bar{S}_{j}^{F, G}=\sup _{z}\left(\sqrt{1-\hat{\lambda}} \mathrm{I}_{j}\left(z ; \mathrm{B}^{*} \circ \hat{G}_{M}\right)-\sqrt{\hat{\lambda}} \mathrm{I}_{j}\left(z ; \mathrm{B}^{*} \circ \hat{F}_{N}\right)\right),
$$

where $\hat{\lambda}=N /(N+M)$. We can again define a corresponding Brownian Bridge process for cumulative distribution function $G$. Let $\left\{V_{i}\right\}_{i=1}^{M}$ denotes a sequence of i.i.d. standard normal random variables that are independent of the samples, we can then give the process $\mathrm{B}^{*} \circ \hat{G}_{M}$, evaluated at each value of $z$, as $\mathrm{B}^{*}\left(z ; \hat{G}_{M}\right)=\frac{1}{\sqrt{M}} \sum_{i=1}^{M}\left(1\left(Y_{i} \leq z\right)-\hat{G}_{M}(z)\right) V_{i}$.

In both cases, the probability that a test statistic using random variables exceeds that using the empirical sample is computed. The approximate p-values and the decision rules for rejecting the null hypotheses are: 


$$
\begin{aligned}
& \text { "Reject } H_{0} \text { if } \hat{p}_{j}^{F} \cong \frac{1}{R} \sum_{r=1}^{R} 1\left(\bar{S}_{j, r}^{F}>\hat{S}_{j}\right)<\alpha ”, \\
& \text { "Reject } H_{0} \text { if } \hat{p}_{j}^{F, G} \cong \frac{1}{R} \sum_{r=1}^{R} 1\left(\bar{S}_{j, r}^{F, G}>\hat{S}_{j}\right)<\alpha ”,
\end{aligned}
$$

where $R$ is the number of replications used in the simulation, and $\alpha$ is the specified significance level.

The other method to obtain exact p-values used by Barrett and Donald (2003) tests is the bootstrap. An advantage of the bootstrap relative to the simulation method is that we now do not necessarily need to characterize the distribution. We follow Barrett and Donald (2003) and use three different bootstrap methods. The first test statistic using the bootstrap (KSB1) is:

$$
\bar{S}_{j, b}^{F}=\sqrt{N} \sup _{z}\left(\mathrm{I}_{j}\left(z ; \hat{F}_{N}^{*}\right)-\mathrm{I}_{j}\left(z ; \hat{F}_{N}\right)\right)
$$

where $\mathrm{I}_{j}\left(z ; \hat{F}_{N}^{*}\right)$ is the analogue of Equation (10) for a random sample of size $N$ drawn from $\mathrm{X}=\left\{X_{1}, \ldots, X_{N}\right\}$. The second test statistic using the bootstrap (KSB2) is:

$$
\bar{S}_{j, b 1}^{F, G}=\sqrt{\frac{N \times M}{N+M}} \sup _{z}\left(\mathrm{I}_{j}\left(z ; \hat{G}_{M}^{*}\right)-\mathrm{I}_{j}\left(z ; \hat{F}_{N}^{*}\right)\right)
$$

where $\mathrm{I}_{j}\left(z ; \hat{G}_{M}^{*}\right)$ is the analogue of Equation (11) for a random sample of size $M$ drawn from the combined sample $\mathrm{Z}=\left\{X_{1}, \ldots, X_{N}, Y_{1}, \ldots, Y_{M}\right\}$, and $\mathrm{I}_{j}\left(z ; \hat{F}_{N}^{*}\right)$ is the analogue of Equation (10) for a random sample of size $N$ drawn from the combined sample $\mathrm{Z}=\left\{X_{1}, \ldots, X_{N}, Y_{1}, \ldots, Y_{M}\right\}$. Finally, the third test statistic using the bootstrap (KSB3) is:

$$
\bar{S}_{j, b 2}^{F, G}=\sqrt{\frac{N \times M}{N+M}} \sup _{z}\left(\left(\mathrm{I}_{j}\left(z ; \hat{G}_{M}^{*}\right)-\mathrm{I}_{j}\left(z ; \hat{G}_{M}\right)\right)-\left(\mathrm{I}_{j}\left(z ; \hat{F}_{N}^{*}\right)-\mathrm{I}_{j}\left(z ; \hat{F}_{N}\right)\right)\right),
$$


where $\mathrm{I}_{j}\left(z ; \hat{G}_{M}^{*}\right)$ is the analogue of Equation (11) for a random sample of size $M$ drawn from the sample $\mathrm{Y}=\left\{Y_{1}, \ldots, Y_{M}\right\}$, and $\mathrm{I}_{j}\left(z ; \hat{F}_{N}^{*}\right)$ analogue of Equation (10) for a random sample of size $N$ drawn from the sample $\mathrm{X}=\left\{X_{1}, \ldots, X_{N}\right\}$. In this case, the two draws are independent.

In each of the three bootstrap methods described above, we are interested in computing the probability that the test statistic using random variables exceeds the value of the test statistic using the empirical sample. The exact p-values and the decision rules for rejecting the null hypotheses in the case of KSB1, KSB2, and KSB3 respectively are:

$$
\begin{aligned}
& \text { "Reject } H_{0} \text { if } \tilde{p}_{j, b}^{F} \cong \frac{1}{R} \sum_{r=1}^{R} 1\left(\bar{S}_{j, b, r}^{F}>\hat{S}_{j}\right)<\alpha ”, \\
& \text { "Reject } H_{0} \text { if } \tilde{p}_{j, b 1}^{F, G} \cong \frac{1}{R} \sum_{r=1}^{R} 1\left(\bar{S}_{j, b 1, r}^{F, G}>\hat{S}_{j}\right)<\alpha ”, \\
& \text { "Reject } H_{0} \text { if } \tilde{p}_{j, b 2}^{F, G} \cong \frac{1}{R} \sum_{r=1}^{R} 1\left(\bar{S}_{j, b 2, r}^{F, G}>\hat{S}_{j}\right)<\alpha ”,
\end{aligned}
$$

where $R$ is the number of replications used in the bootstrap simulation, and $\alpha$ is the specified significance level. To sum up, we use two test statistics from simulation and three from bootstrap to obtain the p-values used to test for various orders of stochastic dominance. In the case of first-order stochastic dominance, since an analytic solution is available, we are not required to use either simulation or bootstrapping to obtain the exact p-value. 


\section{References}

Anderson, G., 1996. Nonparametric tests of stochastic dominance in income distributions. Econometrica 64, 1183-1193.

Barrett, G. and Donald, S. 2003. Consistent tests for stochastic dominance. Econometrica 71, 71-104.

Capaul, C., Rowley, I., and Sharpe, W.F. 1993. International value and growth stock returns. Financial Analysts Journal, January/February, 27-36.

Chan, L.K.C., Hamao, Y., and Lakonishok, J. 1991. Fundamentals and stock returns in Japan. Journal of Finance 46, 1739-1764.

Chan, L.K.C., Hamao, Y., and Lakonishok, J. 1993. Can fundamentals predict Japanese stock returns? Financial Analysts Journal, July/August, 63-69.

Copeland, T. E., Weston, J. F., and Shastri, K. 2005. Financial Theory and Corporate Policy, 4th Edition, Pearson Addison Wesley.

Davidson, R. and Duclos, J.-Y. 2000. Statistical inference for stochastic dominance and for the measurement of poverty and inequality. Econometrica 68, 1435-1464.

De Bondt, W.F.M. and Thaler, R. 1985. Does the stock market overreact? Journal of Finance 40, 793-805.

Fama, E.F. and French, K.R. 1992. The cross-section of expected returns. Journal of Finance 47, 427-465.

Fama, E.F. and French, K.R. 1993. Common risk factors in the returns on stocks and bonds. Journal of Financial Economics 33, 3-56.

Fama, E.F. and French, K.R. 1998. Value versus growth: The new international evidence. Journal of Finance 53, 1975-1999.

Gomes, J. F., Kogan, L., and Zhang, L. 2003. Equilibrium cross section of returns. Journal of Political Economy 111, 693-732.

Graham, B. and Dodd, D. 1934. Security Analysis, McGraw-Hill, New York.

Fong, W.M., Wong, W.K., and Lean, H.H. 2005. International momentum strategies: A stochastic dominance approach. Journal of Financial Markets 8, 89-109.

Harvey, C.R. and Siddique, A. 2000. Conditional skewness in asset pricing tests. Journal of Finance 55, 1263-1294. 
Haugen, R., 1994. The New Finance: The Case Against Efficient Markets, Prentice-Hall, Englewood Cliffs, N.J.

Huang, C.-F. and Litzenberger, R.H. 1988. Foundations for Financial Economics, PrenticeHall.

Ingersoll, J.E., 1987. Theory of Financial Decision Making, Rowman and Littlefield.

Joy, O.M. and Porter, R.B., 1974. Stochastic dominance and mutual fund performance. Journal of Financial and Quantitative Analysis 9, 25-31.

Kogan, L. 2004. Asset prices and real investment. Journal of Financial Economics 73, 411432.

Kothari, S.P., Shanken, J., and Sloan, R.G. 1995. Another look at the cross-section of expected stock returns. Journal of Finance 50, 185-224.

Lakonishok, J., Shleifer, A., and Vishny, R.W. 1994. Contrarian investment, extrapolation, and risk. Journal of Finance 49, 1541-1578.

McFadden, D. 1989. Testing for stochastic dominance. In T.B. Fomby and T.K. Seo (Eds.), Studies in the Economics of Uncertainty: In Honor of Josef Hadar, New York, Berlin, London and Tokyo: Springer.

Lo, A.W. and MacKinlay, S.C. 1990. Data-snooping biases in tests of financial asset pricing models. Review of Financial Studies 3, 431-468.

Petkova, R. and Zhang, L. 2005. Is value riskier than growth? Journal of Financial Economics 78, 187-202.

Porter, R.B. 1973. An empirical comparison of stochastic dominance and mean-variance portfolio choice criteria. Journal of Financial and Quantitative Analysis 8, 587-608.

Porter, R.B. and Gaumnitz, J.E. 1972. Stochastic dominance vs. mean-variance analysis: An empirical evaluation. America Economic Review 62, 438-446.

Post, T. 2003. Empirical tests for stochastic dominance efficiency. Journal of Finance 58, 1905-1931.

Rosenberg, B., Reid, K., and Lanstein, R. 1985. Persuasive evidence of market inefficiency. Journal of Portfolio Management 11, 9-11.

Tehranian, H. 1980. Empirical studies in portfolio performance using higher degrees of stochastic dominance. Journal of Finance 35, 159-171.

Zhang, L. 2005. The value premium. Journal of Finance 60, 67-104. 
Table 1. Descriptive Statistics for Monthly Returns of Equally Weighted Value Portfolios and Growth Portfolios

Value and growth portfolios are created by sorting stocks listed on NYSE, AMEX and Nasdaq on the basis of book-to-market (BE/ME), earnings-to-price (E/P) and cash flow-to-price (CF/P) ratios. The value portfolios contain firms in the top 30\% of corresponding ratio, and the growth portfolios contain firms in the bottom 30\%. Panel A presents the descriptive statistics for the full sample period (1951/07-2003/12). Panel B presents the descriptive statistics for the Lakonishok, Shleifer, and Vishny (1994, LSV) sample period (1963/041990/04). AC1 is the autocorrelation coefficients for the $1^{\text {st }}$ lag of each series.

\begin{tabular}{|c|c|c|c|c|c|c|}
\hline & Mean & St Dev & Min & Max & Median & AC1 \\
\hline \multicolumn{7}{|c|}{ Panel A. Full Sample Period (1951/07-2003/12) } \\
\hline Low BE/ME Portfolio & 0.0093 & 0.0625 & -0.3097 & 0.3303 & 0.0120 & 0.176 \\
\hline High BE/ME Portfolio & 0.0167 & 0.0534 & -0.2546 & 0.3536 & 0.0164 & 0.222 \\
\hline Low E/P Portfolio & 0.0105 & 0.0576 & -0.2950 & 0.2693 & 0.0118 & 0.178 \\
\hline High E/P Portfolio & 0.0165 & 0.0488 & -0.2369 & 0.3250 & 0.0185 & 0.213 \\
\hline Low CF/P Portfolio & 0.0103 & 0.0570 & -0.2981 & 0.2715 & 0.0119 & 0.182 \\
\hline High CF/P Portfolio & 0.0165 & 0.0500 & -0.2491 & 0.3239 & 0.0186 & 0.205 \\
\hline \multicolumn{7}{|c|}{ Panel B. LSV Sample Period (1963/04-1990/04) } \\
\hline Low BE/ME Portfolio & 0.0088 & 0.0647 & -0.3097 & 0.2527 & 0.0074 & 0.197 \\
\hline High BE/ME Portfolio & 0.0169 & 0.0590 & -0.2546 & 0.3536 & 0.0178 & 0.204 \\
\hline Low E/P Portfolio & 0.0102 & 0.0642 & -0.2950 & 0.2693 & 0.0061 & 0.194 \\
\hline High E/P Portfolio & 0.0164 & 0.0554 & -0.2369 & 0.3250 & 0.0180 & 0.190 \\
\hline Low CF/P Portfolio & 0.0096 & 0.0637 & -0.2981 & 0.2715 & 0.0065 & 0.194 \\
\hline High CF/P Portfolio & 0.0170 & 0.0564 & -0.2491 & 0.3239 & 0.0169 & 0.181 \\
\hline
\end{tabular}


Table 2. Stochastic Dominance Tests for Equally Weighted Value and Growth Portfolios for the Full Sample Period (1951/07-2003/12)

In this table we report the results of the first-, second-, and third-order stochastic dominance tests for the full sample period (1951/07-2003/12). We report results according to the Barrett and Donald (2003) two-step test procedure. We first test whether the cumulative distribution function of the value portfolio return stochastically dominates the cumulative distribution of the growth portfolio return. The results are labelled as 'Value Portfolio SDs Growth Portfolio'. Second, we report results of tests for the converse hypothesis of whether the cumulative distribution function of the growth portfolio return stochastically dominates the cumulative distribution function of the value portfolio. These results are labelled as 'Growth Portfolio SDs Value Portfolio'. Three different value/growth classification criteria (BE/ME, E/P, and CF/P) are used in the tests. For the first-order stochastic dominance tests, we calculate analytical solution of the p-values from the asymptotic distribution as: $\exp \left(-2\left(\hat{S}_{1}\right)^{2}\right)$. For the second- and third-order stochastic dominance tests, KS1 and KS2 indicate the tests based on two simulation methods. KSB1, KSB2 and KSB3 represent the tests based on three bootstrap methods. P-values are reported in the table.

\begin{tabular}{|c|c|c|c|c|c|c|c|c|c|c|}
\hline $\begin{array}{l}\text { Value/Growth } \\
\text { Definitions }\end{array}$ & \multicolumn{5}{|c|}{ Value Portfolio SDs Growth Portfolio } & \multicolumn{5}{|c|}{ Growth Portfolio SDs Value Portfolio } \\
\hline \multicolumn{11}{|c|}{ Panel A. First-Order SD Test } \\
\hline $\mathrm{BE} / \mathrm{ME}$ & & & 0.632 & & & & & 0.006 & & \\
\hline $\mathrm{E} / \mathrm{P}$ & & & 0.464 & & & & & 0.002 & & \\
\hline \multirow[t]{2}{*}{$\mathrm{CF} / \mathrm{P}$} & & & 0.666 & & & & & 0.007 & & \\
\hline & $\underline{\mathrm{KS} 1}$ & $\underline{\mathrm{KS} 2}$ & $\underline{\mathrm{KSB} 1}$ & $\underline{\text { KSB2 }}$ & $\underline{\text { KSB3 }}$ & $\underline{\mathrm{KS} 1}$ & $\underline{\mathrm{KS} 2}$ & $\underline{\text { KSB1 }}$ & $\underline{\text { KSB2 }}$ & $\underline{\text { KSB3 }}$ \\
\hline \multicolumn{11}{|c|}{ Panel B. Second-Order SD Test } \\
\hline $\mathrm{BE} / \mathrm{ME}$ & 0.813 & 0.855 & 0.791 & 0.815 & 0.800 & 0.002 & 0.004 & 0.007 & 0.005 & 0.005 \\
\hline $\mathrm{E} / \mathrm{P}$ & 0.811 & 0.847 & 0.776 & 0.806 & 0.800 & 0.002 & 0.003 & 0.006 & 0.005 & 0.005 \\
\hline $\mathrm{CF} / \mathrm{P}$ & 0.810 & 0.851 & 0.774 & 0.808 & 0.797 & 0.003 & 0.006 & 0.009 & 0.006 & 0.010 \\
\hline \multicolumn{11}{|c|}{ Panel C. Third-Order SD Test } \\
\hline $\mathrm{BE} / \mathrm{ME}$ & 0.760 & 0.775 & 0.719 & 0.721 & 0.745 & 0.003 & 0.004 & 0.005 & 0.004 & 0.003 \\
\hline $\mathrm{E} / \mathrm{P}$ & 0.758 & 0.781 & 0.705 & 0.728 & 0.748 & 0.008 & 0.003 & 0.006 & 0.005 & 0.006 \\
\hline $\mathrm{CF} / \mathrm{P}$ & 0.759 & 0.785 & 0.708 & 0.728 & 0.748 & 0.013 & 0.003 & 0.009 & 0.006 & 0.007 \\
\hline
\end{tabular}


Table 3. Stochastic Dominance Tests for Equally Weighted Value and Growth Portfolios for the LSV Sample Period (1963/04-1990/04)

In this table we report the results of the first-, second-, and third-order stochastic dominance tests for the LSV sample period (1963/04-1990/04). We report results according to the Barrett and Donald (2003) two-step test procedure. We first test whether the cumulative distribution function of the value portfolio return stochastically dominates the cumulative distribution of the growth portfolio return. The results are labelled as 'Value Portfolio SDs Growth Portfolio'. Second, we report results of tests for the converse hypothesis of whether the cumulative distribution function of the growth portfolio return stochastically dominates the cumulative distribution function of the value portfolio. These results are labelled as 'Growth Portfolio SDs Value Portfolio'. Three different value/growth classification criteria (BE/ME, E/P, and CF/P) are used in the tests. For the first-order stochastic dominance tests, we calculate analytical solution of the p-values from the asymptotic distribution as: $\exp \left(-2\left(\hat{S}_{1}\right)^{2}\right)$. For the second- and third-order stochastic dominance tests, KS1 and KS2 indicate the tests based on two simulation methods. KSB1, KSB2 and KSB3 represent the tests based on three bootstrap methods. P-values are reported in the table.

\begin{tabular}{|c|c|c|c|c|c|c|c|c|c|c|}
\hline $\begin{array}{l}\text { Value/Growth } \\
\text { Definitions }\end{array}$ & \multicolumn{5}{|c|}{ Value Portfolio SDs Growth Portfolio } & \multicolumn{5}{|c|}{ Growth Portfolio SDs Value Portfolio } \\
\hline \multicolumn{11}{|c|}{ Panel A. First-Order SD Test } \\
\hline $\mathrm{BE} / \mathrm{ME}$ & & & 0.642 & & & & & 0.035 & & \\
\hline E/P & & & 0.642 & & & & & 0.029 & & \\
\hline \multirow{2}{*}{ CF/P } & & & 0.776 & & & & & 0.043 & & \\
\hline & $\underline{\mathrm{KS} 1}$ & $\underline{\mathrm{KS} 2}$ & $\underline{\text { KSB1 }}$ & $\underline{\text { KSB2 }}$ & $\underline{\text { KSB3 }}$ & $\underline{\mathrm{KS} 1}$ & $\underline{\mathrm{KS} 2}$ & $\underline{\text { KSB1 }}$ & $\underline{\text { KSB2 }}$ & $\underline{\text { KSB3 }}$ \\
\hline \multicolumn{11}{|c|}{ Panel B. Second-Order SD Test } \\
\hline $\mathrm{BE} / \mathrm{ME}$ & 0.795 & 0.841 & 0.730 & 0.794 & 0.734 & 0.028 & 0.039 & 0.031 & 0.043 & 0.040 \\
\hline $\mathrm{E} / \mathrm{P}$ & 0.795 & 0.844 & 0.743 & 0.800 & 0.738 & 0.029 & 0.046 & 0.032 & 0.051 & 0.053 \\
\hline $\mathrm{CF} / \mathrm{P}$ & 0.797 & 0.852 & 0.739 & 0.793 & 0.735 & 0.027 & 0.037 & 0.030 & 0.048 & 0.042 \\
\hline \multicolumn{11}{|c|}{ Panel C. Third-Order SD Test } \\
\hline $\mathrm{BE} / \mathrm{ME}$ & 0.717 & 0.761 & 0.649 & 0.734 & 0.739 & 0.041 & 0.030 & 0.018 & 0.040 & 0.029 \\
\hline $\mathrm{E} / \mathrm{P}$ & 0.727 & 0.767 & 0.662 & 0.738 & 0.741 & 0.075 & 0.046 & 0.036 & 0.059 & 0.047 \\
\hline $\mathrm{CF} / \mathrm{P}$ & 0.722 & 0.773 & 0.654 & 0.731 & 0.738 & 0.057 & 0.031 & 0.019 & 0.048 & 0.042 \\
\hline
\end{tabular}


Table 4. Stochastic Dominance Tests for Equally Weighted Value and Growth Portfolios for the Full Sample (1951/07-2003/12) Boom Period

In this table we report the results of the first-, second-, and third-order stochastic dominance tests for the full sample (1951/07-2003/12) boom period. We report results according to the Barrett and Donald (2003) twostep test procedure. We first test whether the cumulative distribution function of the value portfolio return stochastically dominates the cumulative distribution of the growth portfolio return. The results are labelled as 'Value Portfolio SDs Growth Portfolio'. Second, we report results of tests for the converse hypothesis of whether the cumulative distribution function of the growth portfolio return stochastically dominates the cumulative distribution function of the value portfolio. These results are labelled as 'Growth Portfolio SDs Value Portfolio'. Three different value/growth classification criteria (BE/ME, E/P, and CF/P) are used in the tests. For the first-order stochastic dominance tests, we calculate analytical solution of the p-values from the asymptotic distribution as: $\exp \left(-2\left(\hat{S}_{1}\right)^{2}\right)$. For the second- and third-order stochastic dominance tests, KS1 and KS2 indicate the tests based on two simulation methods. KSB1, KSB2 and KSB3 represent the tests based on three bootstrap methods. P-values are reported in the table.

\begin{tabular}{|c|c|c|c|c|c|c|c|c|c|c|}
\hline $\begin{array}{l}\text { Value/Growth } \\
\text { Definitions }\end{array}$ & \multicolumn{5}{|c|}{ Value Portfolio SDs Growth Portfolio } & \multicolumn{5}{|c|}{ Growth Portfolio SDs Value Portfolio } \\
\hline \multicolumn{11}{|c|}{ Panel A. First-Order SD Test } \\
\hline $\mathrm{BE} / \mathrm{ME}$ & & & 0.730 & & & & & 0.016 & & \\
\hline E/P & & & 0.511 & & & & & 0.004 & & \\
\hline \multirow{2}{*}{ CF/P } & & & 0.830 & & & & & 0.016 & & \\
\hline & $\underline{\mathrm{KS} 1}$ & $\underline{\mathrm{KS} 2}$ & $\underline{\text { KSB1 }}$ & $\underline{\text { KSB2 }}$ & $\underline{\text { KSB3 }}$ & $\underline{\mathrm{KS} 1}$ & $\underline{\mathrm{KS} 2}$ & $\underline{\text { KSB1 }}$ & $\underline{\text { KSB2 }}$ & $\underline{\text { KSB3 }}$ \\
\hline \multicolumn{11}{|c|}{ Panel B. Second-Order SD Test } \\
\hline $\mathrm{BE} / \mathrm{ME}$ & 0.808 & 0.831 & 0.744 & 0.789 & 0.782 & 0.005 & 0.009 & 0.003 & 0.007 & 0.002 \\
\hline $\mathrm{E} / \mathrm{P}$ & 0.800 & 0.811 & 0.714 & 0.786 & 0.779 & 0.005 & 0.016 & 0.003 & 0.009 & 0.009 \\
\hline $\mathrm{CF} / \mathrm{P}$ & 0.799 & 0.820 & 0.716 & 0.780 & 0.782 & 0.013 & 0.022 & 0.010 & 0.017 & 0.020 \\
\hline \multicolumn{11}{|c|}{ Panel C. Third-Order SD Test } \\
\hline $\mathrm{BE} / \mathrm{ME}$ & 0.753 & 0.755 & 0.654 & 0.713 & 0.756 & 0.007 & 0.005 & 0.000 & 0.003 & 0.004 \\
\hline $\mathrm{E} / \mathrm{P}$ & 0.736 & 0.748 & 0.629 & 0.714 & 0.740 & 0.030 & 0.012 & 0.006 & 0.005 & 0.011 \\
\hline $\mathrm{CF} / \mathrm{P}$ & 0.737 & 0.756 & 0.634 & 0.707 & 0.746 & 0.038 & 0.015 & 0.010 & 0.010 & 0.014 \\
\hline
\end{tabular}


Table 5. Stochastic Dominance Tests for Equally Weighted Value and Growth Portfolios for the LSV Sample (1963/04-1990/04) Boom Period

In this table we report the results of the first-, second-, and third-order stochastic dominance tests for the LSV sample (1963/04-1990/04) boom period. We report results according to the Barrett and Donald (2003) twostep test procedure. We first test whether the cumulative distribution function of the value portfolio return stochastically dominates the cumulative distribution of the growth portfolio return. The results are labelled as 'Value Portfolio SDs Growth Portfolio'. Second, we report results of tests for the converse hypothesis of whether the cumulative distribution function of the growth portfolio return stochastically dominates the cumulative distribution function of the value portfolio. These results are labelled as 'Growth Portfolio SDs Value Portfolio'. Three different value/growth classification criteria (BE/ME, E/P, and CF/P) are used in the tests. For the first-order stochastic dominance tests, we calculate analytical solution of the p-values from the asymptotic distribution as: $\exp \left(-2\left(\hat{S}_{1}\right)^{2}\right)$. For the second- and third-order stochastic dominance tests, KS1 and KS2 indicate the tests based on two simulation methods. KSB1, KSB2 and KSB3 represent the tests based on three bootstrap methods. P-values are reported in the table.

\begin{tabular}{|c|c|c|c|c|c|c|c|c|c|c|}
\hline $\begin{array}{l}\text { Value/Growth } \\
\text { Definitions }\end{array}$ & \multicolumn{5}{|c|}{$\underline{\text { Value Portfolio SDs Growth Portfolio }}$} & \multicolumn{5}{|c|}{ Growth Portfolio SDs Value Portfolio } \\
\hline \multicolumn{11}{|c|}{ Panel A. First-Order SD Test } \\
\hline $\mathrm{BE} / \mathrm{ME}$ & & & 0.746 & & & & & 0.058 & & \\
\hline $\mathrm{E} / \mathrm{P}$ & & & 0.593 & & & & & 0.071 & & \\
\hline \multirow[t]{2}{*}{$\mathrm{CF} / \mathrm{P}$} & & & 0.837 & & & & & 0.086 & & \\
\hline & $\underline{\mathrm{KS} 1}$ & $\underline{\mathrm{KS} 2}$ & $\underline{\text { KSB1 }}$ & $\underline{\mathrm{KSB} 2}$ & $\underline{\text { KSB3 }}$ & $\underline{\mathrm{KS} 1}$ & $\underline{\mathrm{KS} 2}$ & KSB1 & KSB2 & $\underline{\text { KSB3 }}$ \\
\hline \multicolumn{11}{|c|}{ Panel B. Second-Order SD Test } \\
\hline $\mathrm{BE} / \mathrm{ME}$ & 0.772 & 0.819 & 0.699 & 0.792 & 0.763 & 0.062 & 0.069 & 0.054 & 0.079 & 0.071 \\
\hline $\mathrm{E} / \mathrm{P}$ & 0.776 & 0.814 & 0.701 & 0.791 & 0.760 & 0.064 & 0.074 & 0.052 & 0.086 & 0.073 \\
\hline $\mathrm{CF} / \mathrm{P}$ & 0.774 & 0.821 & 0.704 & 0.792 & 0.758 & 0.061 & 0.071 & 0.049 & 0.084 & 0.069 \\
\hline \multicolumn{11}{|c|}{ Panel C. Third-Order SD Test } \\
\hline $\mathrm{BE} / \mathrm{ME}$ & 0.706 & 0.738 & 0.598 & 0.731 & 0.720 & 0.095 & 0.049 & 0.039 & 0.062 & 0.056 \\
\hline $\mathrm{E} / \mathrm{P}$ & 0.706 & 0.734 & 0.601 & 0.732 & 0.726 & 0.124 & 0.071 & 0.061 & 0.093 & 0.071 \\
\hline $\mathrm{CF} / \mathrm{P}$ & 0.710 & 0.736 & 0.605 & 0.729 & 0.718 & 0.104 & 0.053 & 0.047 & 0.070 & 0.055 \\
\hline
\end{tabular}


Table 6. Stochastic Dominance Tests for Equally Weighted Value and Growth Portfolios for the Full Sample (1951/07-2003/12) Recession Period

In this table we report the results of the first-, second-, and third-order stochastic dominance tests for the full sample (1951/07-2003/12) recession period. We report results according to the Barrett and Donald (2003) two-step test procedure. We first test whether the cumulative distribution function of the value portfolio return stochastically dominates the cumulative distribution of the growth portfolio return. The results are labelled as 'Value Portfolio SDs Growth Portfolio'. Second, we report results of tests for the converse hypothesis of whether the cumulative distribution function of the growth portfolio return stochastically dominates the cumulative distribution function of the value portfolio. These results are labelled as 'Growth Portfolio SDs Value Portfolio'. Three different value/growth classification criteria (BE/ME, E/P, and CF/P) are used in the tests. For the first-order stochastic dominance tests, we calculate analytical solution of the p-values from the asymptotic distribution as: $\exp \left(-2\left(\hat{S}_{1}\right)^{2}\right)$. For the second- and third-order stochastic dominance tests, KS1 and KS2 indicate the tests based on two simulation methods. KSB1, KSB2 and KSB3 represent the tests based on three bootstrap methods. P-values are reported in the table.

\begin{tabular}{|c|c|c|c|c|c|c|c|c|c|c|}
\hline $\begin{array}{l}\text { Value/Growth } \\
\text { Definitions }\end{array}$ & \multicolumn{5}{|c|}{ Value Portfolio SDs Growth Portfolio } & \multicolumn{5}{|c|}{ Growth Portfolio SDs Value Portfolio } \\
\hline \multicolumn{11}{|c|}{ Panel A. First-Order SD Test } \\
\hline $\mathrm{BE} / \mathrm{ME}$ & & & 0.679 & & & & & 0.272 & & \\
\hline E/P & & & 0.764 & & & & & 0.272 & & \\
\hline \multirow{2}{*}{ CF/P } & & & 0.590 & & & & & 0.213 & & \\
\hline & $\underline{\mathrm{KS} 1}$ & $\underline{\mathrm{KS} 2}$ & $\underline{\text { KSB1 }}$ & $\underline{\text { KSB2 }}$ & $\underline{\text { KSB3 }}$ & $\underline{\mathrm{KS} 1}$ & $\underline{\mathrm{KS} 2}$ & $\underline{\text { KSB1 }}$ & $\underline{\text { KSB2 }}$ & $\underline{\text { KSB3 }}$ \\
\hline \multicolumn{11}{|c|}{ Panel B. Second-Order SD Test } \\
\hline $\mathrm{BE} / \mathrm{ME}$ & 0.794 & 0.827 & 0.727 & 0.776 & 0.765 & 0.266 & 0.264 & 0.239 & 0.256 & 0.276 \\
\hline $\mathrm{E} / \mathrm{P}$ & 0.798 & 0.811 & 0.718 & 0.763 & 0.765 & 0.194 & 0.213 & 0.192 & 0.217 & 0.233 \\
\hline $\mathrm{CF} / \mathrm{P}$ & 0.791 & 0.810 & 0.716 & 0.768 & 0.766 & 0.192 & 0.213 & 0.189 & 0.209 & 0.226 \\
\hline \multicolumn{11}{|c|}{ Panel C. Third-Order SD Test } \\
\hline $\mathrm{BE} / \mathrm{ME}$ & 0.756 & 0.765 & 0.671 & 0.712 & 0.747 & 0.270 & 0.238 & 0.213 & 0.244 & 0.241 \\
\hline $\mathrm{E} / \mathrm{P}$ & 0.742 & 0.755 & 0.661 & 0.701 & 0.731 & 0.198 & 0.173 & 0.147 & 0.166 & 0.175 \\
\hline $\mathrm{CF} / \mathrm{P}$ & 0.734 & 0.745 & 0.663 & 0.701 & 0.727 & 0.206 & 0.181 & 0.154 & 0.170 & 0.173 \\
\hline
\end{tabular}


Table 7. Stochastic Dominance Tests for Equally Weighted Value and Growth Portfolios for the LSV Sample (1963/04-1990/04) Recession Period

In this table we report the results of the first-, second-, and third-order stochastic dominance tests for the LSV sample (1963/04-1990/04) recession period. We report results according to the Barrett and Donald (2003) two-step test procedure. We first test whether the cumulative distribution function of the value portfolio return stochastically dominates the cumulative distribution of the growth portfolio return. The results are labelled as 'Value Portfolio SDs Growth Portfolio'. Second, we report results of tests for the converse hypothesis of whether the cumulative distribution function of the growth portfolio return stochastically dominates the cumulative distribution function of the value portfolio. These results are labelled as 'Growth Portfolio SDs Value Portfolio'. Three different value/growth classification criteria (BE/ME, E/P, and CF/P) are used in the tests. For the first-order stochastic dominance tests, we calculate analytical solution of the p-values from the asymptotic distribution as: $\exp \left(-2\left(\hat{S}_{1}\right)^{2}\right)$. For the second- and third-order stochastic dominance tests, KS1 and KS2 indicate the tests based on two simulation methods. KSB1, KSB2 and KSB3 represent the tests based on three bootstrap methods. P-values are reported in the table.

\begin{tabular}{|c|c|c|c|c|c|c|c|c|c|c|}
\hline $\begin{array}{c}\text { Value/Growth } \\
\text { Definitions }\end{array}$ & \multicolumn{5}{|c|}{ Value Portfolio SDs Growth Portfolio } & \multicolumn{5}{|c|}{ Growth Portfolio SDs Value Portfolio } \\
\hline \multicolumn{11}{|c|}{ Panel A. First-Order SD Test } \\
\hline $\mathrm{BE} / \mathrm{ME}$ & & & 0.721 & & & & & 0.130 & & \\
\hline $\mathrm{E} / \mathrm{P}$ & & & 0.832 & & & & & 0.368 & & \\
\hline \multirow[t]{2}{*}{$\mathrm{CF} / \mathrm{P}$} & & & 0.721 & & & & & 0.271 & & \\
\hline & $\underline{\mathrm{KS} 1}$ & $\underline{\mathrm{KS}} 2$ & $\underline{\mathrm{KSB} 1}$ & $\underline{\mathrm{KSB} 2}$ & $\underline{\text { KSB3}}$ & $\underline{\text { KS1 }}$ & $\underline{\mathrm{KS} 2}$ & $\underline{\text { KSB1 }}$ & $\underline{\mathrm{KSB} 2}$ & $\underline{\text { KSB3 }}$ \\
\hline \multicolumn{11}{|c|}{ Panel B. Second-Order SD Test } \\
\hline $\mathrm{BE} / \mathrm{ME}$ & 0.778 & 0.804 & 0.710 & 0.773 & 0.761 & 0.189 & 0.193 & 0.192 & 0.226 & 0.212 \\
\hline $\mathrm{E} / \mathrm{P}$ & 0.782 & 0.791 & 0.710 & 0.759 & 0.749 & 0.179 & 0.190 & 0.181 & 0.234 & 0.210 \\
\hline $\mathrm{CF} / \mathrm{P}$ & 0.772 & 0.795 & 0.707 & 0.761 & 0.749 & 0.180 & 0.191 & 0.190 & 0.235 & 0.208 \\
\hline \multicolumn{11}{|c|}{ Panel C. Third-Order SD Test } \\
\hline $\mathrm{BE} / \mathrm{ME}$ & 0.737 & 0.746 & 0.642 & 0.707 & 0.726 & 0.186 & 0.157 & 0.145 & 0.188 & 0.153 \\
\hline $\mathrm{E} / \mathrm{P}$ & 0.735 & 0.727 & 0.642 & 0.708 & 0.711 & 0.198 & 0.162 & 0.137 & 0.197 & 0.164 \\
\hline $\mathrm{CF} / \mathrm{P}$ & 0.722 & 0.736 & 0.641 & 0.705 & 0.721 & 0.190 & 0.153 & 0.131 & 0.194 & 0.162 \\
\hline
\end{tabular}

